\title{
A new problem in inflammatory bladder diseases: Use of mobile phones!
}

Orhan Koca', Ali Murat Gokce ${ }^{1}$, Mehmet Akyuz', Feriha Ercan², Necati Yurdakul2, Muhammet Ihsan Karaman $^{1}$

${ }^{1}$ Department of Urology, Haydarpasa Numune Training and Research Hospital and ${ }^{2}$ Department of Histology and Embryology, Marmara University School of Medicine, Istanbul, Turkey

\section{ABSTRACT}

Purpose: Technological developments provide a lot of conveniences to our lives. This issue is one of the risks that arise along with these conveniences. In our study we tried to understand the impact of electromagnetic waves from mobile phones on bladder tissue. Materials and Methods: Twenty-one adult male albino rats were divided into three equal groups. Group 1 was exposed to electromagnetic wave for 8 hours per day for 20 days and then their bladders were taken off immediately. Group 2 was firstly exposed to electromagnetic wave for 8 hours per day for 20 days then secondly another for 20 days without exposition to electromagnetic wave and then their bladders were taken off. Group 3 was the control group and they were not exposed to electromagnetic wave.

Results: Under microscopic examination of bladder tissue, in the first group severe inflammatory cell infiltration was seen in lamina propria and muscle layer in contrast to intact urothelium. In the second group mild inflammatory cell infiltration was seen in lamina propria and muscle layer. The mean scores for the three groups were $5.5 \pm$ $2.5,0.8 \pm 1.3$ and $1.2 \pm 1.5$ respectively. Mean score of group 1 was statistically higher than others $(\mathrm{p}=0.001)$.

Conclusion: Intensive use of mobile phones has negative impact on bladder tissue as well as the other organs. Keeping a minimum level of mobile phone use makes it easy to be kept under control of diseases in which inflammation is an etiologic factor.

\section{ARTICLE INFO}

\section{Key words:}

Urinary Bladder; Cellular Phone;

Electromagnetic Radiation

Int Braz J Urol. 2014; 40: 520-5

Submitted for publication:

September 07, 2013

Accepted after revision:

March 16, 2014

\section{INTRODUCTION}

In daily life people are in electromagnetic field and exposed to electromagnetic wave (EMW). Mobile phones and base stations, which emit electromagnetic waves, are increasingly used. Nowadays studies showed the harmful effects of these waves on human health, so that, this issue is becoming a major health problem. Electromagnetic waves from mobile phones affect human beings by thermal and non-thermal ways (1). Thermal effects are caused by electromagnetic waves absorbed by body and converted to heat that cause raise in body temperature (2). On the other hand, non-thermal effects leads to damage of brain function, sleep disorders and headaches. Also, electromagnetic waves can cause DNA damage (3).

Recently, the incidence of nonmalignant bladder diseases such as interstitial cystitis (IC) and overactive bladder syndrome has been increasing. Etiology of these diseases is still unknown. Mast cell is blamed for etiology of bladder IC (4). Damage of urinary bladder mucosa and activated mast cell has been shown in biopsy series in bladder interstitial disease patients $(5,6)$. 
Technological developments provide a lot of conveniences to our lives. This issue is one of the risks that arise along with these conveniences. In our study we tried to understand the impact of electromagnetic waves from cell phones on bladder tissue.

\section{MATERIALS AND METHODS}

Twenty-one adult male Wistar Albino rats were divided into 3 equal groups. Each group was locked separately in a 40 x $60 \mathrm{~cm}$ standard cage. Group 1 was exposed to mobile phone for 8 hours talk time and 16 hours standby per day for 20 days. Then bladders of these rats were taken off. Group 2 was firstly exposed to EMW for 20 days (same as first group) then secondly waited for 20 days without exposition to electromagnetic wave to the bladders being taken off. Group 3 was the control group and they were observed in laboratory for 20 days without exposition to EMW and then the bladders were also taken off. All rats were housed in an environment with 12 hours light, 12 hours darkness, temperature of $21^{\circ} \mathrm{C}$ and ambient humidity of 40-60\% and food ad libitum (MBD Experimental Animals Feed, Gebze, Turkey) and water supply. In the present study, Philips Genie $90{ }^{\circledR}$ (Singapore) cell phone was used as a 1800$\mathrm{MHz}$ continuous wave electromagnetic energy generator which has the highest specific absorption rate (SAR, $1.52 \mathrm{~W} / \mathrm{kg}$ ) on the market. Mobile phones were fixed $1 \mathrm{~cm}$ above cages. Mobile phones were connected to 24 hours charge and they had 8 hours talk time and 16 hours standby per day. Rats were sacrificed with high dose pentobarbital. An abdominal incision was made to remove the bladders. The bladders were prepared for examination by light and electron microscopy. All experimental protocols were approved by the Animal Care and Use Committee of the Marmara University, School of Medicine, Istanbul, Turkey.

\section{Light Microscopic Preparation}

For histopathologic examination, samples were taken from bladder and they were fixed with $10 \%$ formaldehyde solution then passed through a series of alcohol and became transparent by toluene solution and embedded in paraffin. Approximately $5 \mu \mathrm{m}$ thick paraffın sections were stained with hematoxylin and eosin (HEE) for general morphologic examination. A histopathologic scoring system for examined tissue was used as follows; 0: none, 1: mild, 2: moderate, 3: severe. Damage in urothelium (score 0-3), mucosal inflammatory cell infiltration (score 0-3) and mucosal and muscular inflammatory cell infiltration (score 0-3) were scored in examined tissue. At least 5 microscopic fields were examined for scoring. Two researchers examined all preparations and final score were given by consensus. Total score was between 0-9. For the observation of granulated and degranulated mast cells, $5 \mu \mathrm{m}$ thick paraffin sections were stained with $1 \%$ acidified toluidine blue ( $\mathrm{pH} 2.5)$. All the stained sections were examined by Olympus BX51 photomicroscope (Tokyo, Japan).

\section{paration}

Transmission Electron Microscopy Pre-

For transmission electron microscopic examination, samples were taken from bladder than were fixed with $2.5 \%$ glutaraldehyde in phosphate buffered solution (PBS, 0.1 M, pH 7.4) then post fixed with 1\% osmium tetroxide in PBS. Samples passed through a series of alcohol to dehydration and then polymerized in the Epon 812 at $60^{\circ} \mathrm{C}$. Approximately 60nm thick ultrathin sections were contrasted with uranyl acetate and lead citrate and the sections were observed using a transmission electron microscope (JEOL 1200 EXII TEM, Tokyo, Japan) at $80 \mathrm{kV}$ accelerating voltage and photographed with a side mounted digital camera (Morada Soft Imaging System, Olympus, USA).

\section{Statistical analysis}

For statistical analysis Mann-Whitney U test was used via SPSS $^{\circledR} 13.0$ for Windows. $\mathrm{P}<$ 0.05 was considered statistically significant.

\section{RESULTS}

Microscopic examination of bladder tissue revealed regular morphology in mucosa, muscle and adventitia layers (Figure-1A) and a few granulated mast cells (Figure-1B) in mucosa was seen in the control group (Group 3). In the second group, it was observed regular urothelium morphology, 
Figure 1 (Group 1) - Regular morphology in mucosa, muscle and adventitia layers (A), a few granulated mast cells (B) in lamina propria, regular ultrastructure of urothelium (C). A) H\&E staining, original magnification: $\times 100$; B) Toluidine blue staining, original magnification: $x 400$; C) Electron micrograph, original magnification: $\mathrm{X3000}$.

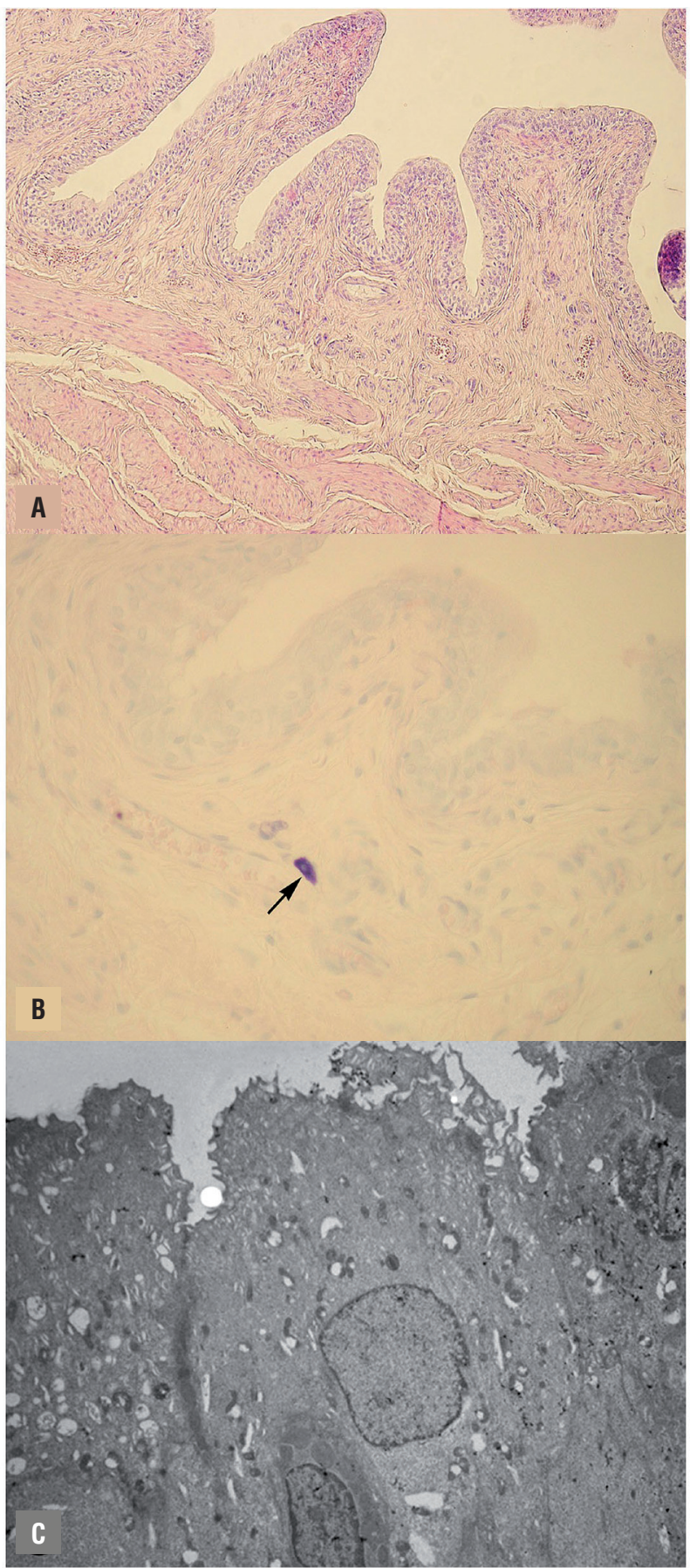

moderate inflammatory cell infiltration in lamina propria and the muscle layer (Figure-2A) and mildly increased both granulated and degranulated mast cells in mucosa (Figure-2B). Finally in the first group, urothelium also displayed regular morphology, severe inflammatory cell infiltration in lamina propria and the muscle layer (Figure$-3 \mathrm{~A})$ and severely increased both granulated and degranulated mast cells (Figure-3B) were observed in mucosa.

In electron microscopic examination of bladder tissue, regular ultrastructure of urothelium was seen in the control group (Group 3) (Figure$-1 \mathrm{C})$. In the second group generally regular morphology was seen in urothelium, however near the lumen of bladder infiltrated mast cells between urothelial cells (Figure-2C) were observed. In first group vacuoles were increased in some urothelial cells and intercellular connections were interrupted (Figure-3C).

The mean scores for the three groups were $5.5 \pm 2.5,0.8 \pm 1.3$ and $1.2 \pm 1.5$ respectively. In the statistical evaluation between groups there was no significant difference between groups 2 and $3(\mathrm{P}>0.05)$. On the other hand, group 1 was significantly higher than the other two groups ( $\mathrm{P}$ $=0.001)$ (Table-1).

\section{DISCUSSION}

Technological developments bring many innovations to our daily lives. While these innovations facilitate our daily lives there are some disadvantages that threaten human health. Electromagnetic waves emitted from hair dryers, computers, microwave ovens and mobile phones, which are being increasingly used have many negative side effects on human health (7-9).

Inflammatory bladder diseases have been increasing day by day. These diseases adversely affect the quality of life of patients. Etiology of these diseases is still not well known. The relationship between EMW and inflammatory bladder disease is one of the topics to be explored.

There are many stimuli of mast cells that are accused in the pathogenesis of bladder, gut and skin diseases. Some of them include antigens, bacteria, chemicals, drugs, radiation, toxins, and 
Figure 2 (Group 2) - Regular morphology in urothelium (u), severe inflammatory cell infiltration (arrow) in lamina propria and muscle layers $(\mathrm{m})(\mathrm{A})$, a few both granulated (arrow) and degranulated (arrowhead) mast cells (B) in lamina propria, regular urothelial cells with intercellular spaces and mast cell (arrow) between the urothelial cells (C). A) H\&E staining, original magnifications: $\mathbf{x} 100$, inserts: $x 200, B)$ Toluidine blue staining, original magnification: $x 400$, insert: $x 1000, C)$ Electron micrograph, original magnification: X5000.

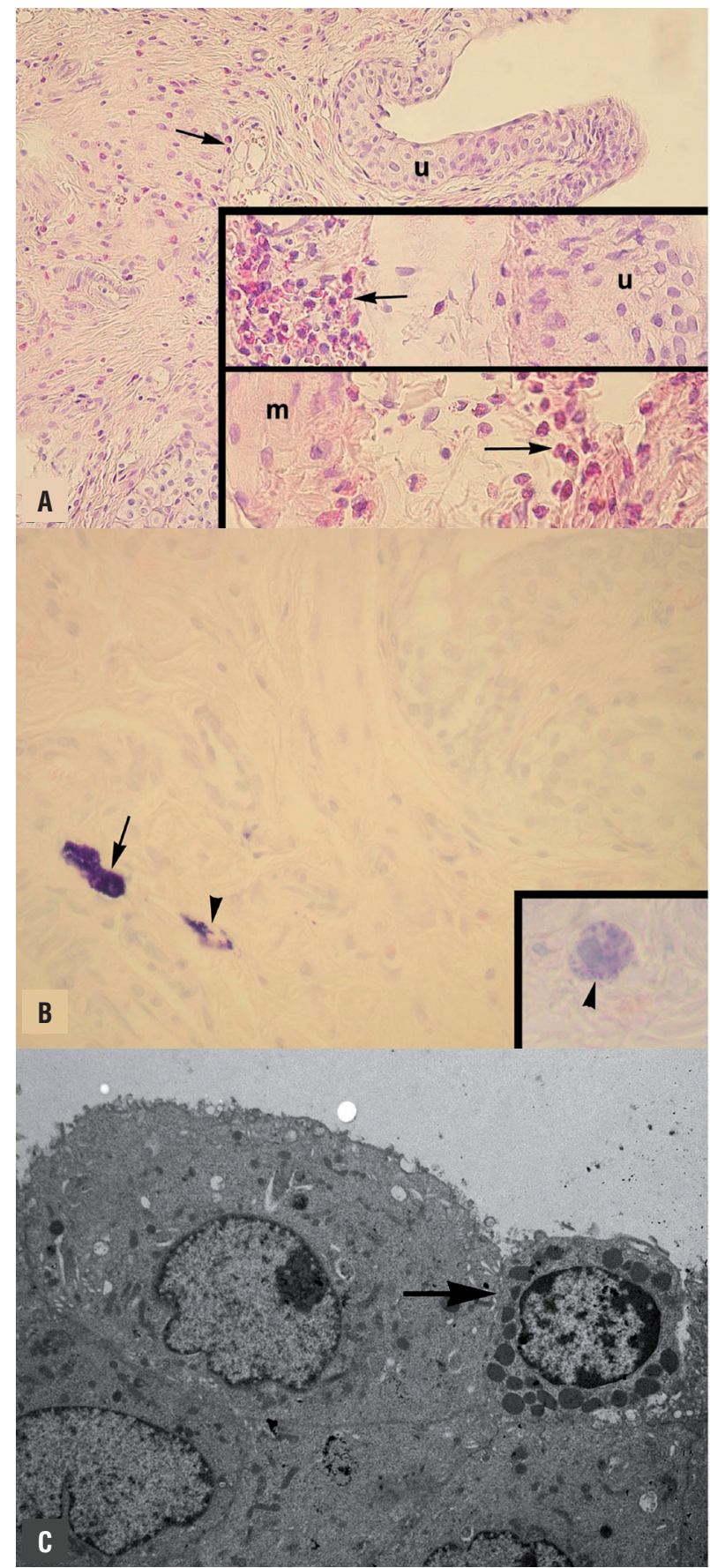

Figure 3 (Group 3): Regular morphology in urothelium (u), severe inflammatory cell infiltration (arrow) in lamina propria and muscle layers $(m)(A)$, severe increase in both granulated (arrow) and degranulated (arrowhead) mast cells (B) in lamina propria, many vacuoles in the cytoplasm of urothelial cells (arrow) (C). A) H\&E staining, original magnifications: $x 100$, inserts: $x 200$, B) Toluidine blue staining, original

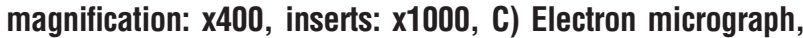
original magnification: X5000.

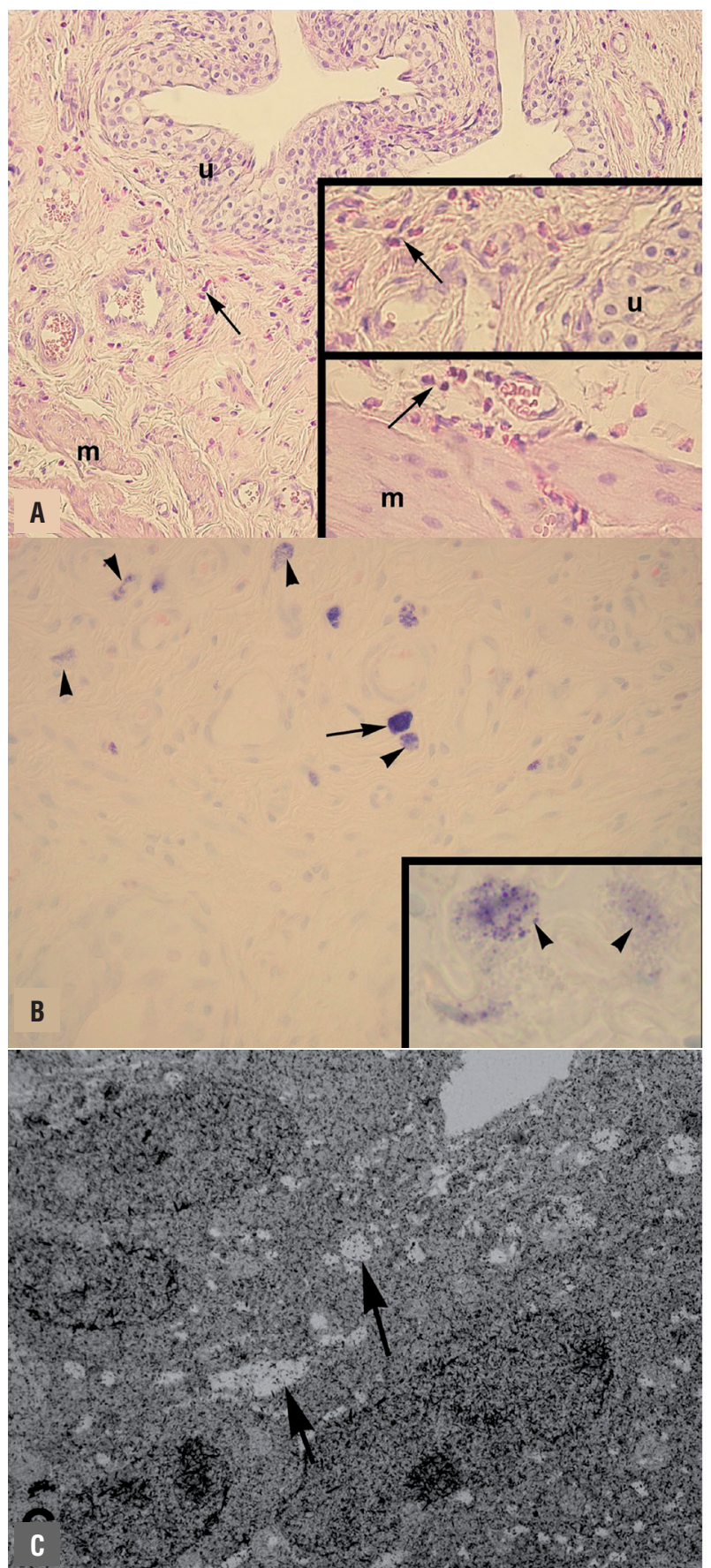


Table 1 - Comparison of the three groups.

\begin{tabular}{lccc}
\hline & Mean \pm SD & Median & Range \\
\hline Group 1 & $5.5 \pm 2.5$ & 6 & 6 \\
Group 2 & $0.8 \pm 1.3$ & 0 & 3 \\
Group 3 & $1.2 \pm 1.5$ & 1.5 & 3 \\
$\mathrm{P}^{*}$ & & $\mathrm{P}<0.05$ & \\
\hline
\end{tabular}

*Between groups 2 and $3 ; p>0.05 ;$ group 1 and group 2-3; $p=0.001$

some viruses (10). In our study we show that use of mobile phones increased mast cell number and activity in bladder tissue. These findings were observed to be reversible with termination of exposure to EMW. But in the clinic the impact of these conditions is not yet known. Clinical trials would determine whether improvement in pathology brings with it a clinical improvement.

The relationship between IC and mast cells has been shown in several clinical trials (4). IC has symptoms like supra pubic/pelvic pain and pollakiuria, and IC is more prevalent in women (4). Mast cells, which are one of the immunological cells derived from bone marrow may have important roles in etiology of non-allergic inflammatory bladder, gastrointestinal and skin diseases in experimental model of inflammation $(4,11,12)$. From our study we suggest an increase in activity of mast cells because there were many of both granulated and degranulated cells in mucosa seen by light microscopic examination. It has been shown in previous studies that IgE and antigens cause mast cell degranulation (10). In our study we show that mobile phones also have the same effect on mast cells.

In models of bladder injury made by intravesical chemical agents, systemic chemical agents, physiologic and physiologic stress stimulants, the importance of glycosaminoglycan (GAG), gap junctions in urothelium, and mast cell activation via neuroimmunendocrine pathway was shown (13). By mast cell activation many proinflammatory mediators can cause damage to the bladder wall (13). In our study we observed increased vacuoles in some urothelial cells and dilatation of intercellular connections in group 1. These findings suggest that with an increase in the number and activation of mast cells the protective layers may be damaged. EMW from mobile phones and their base stations could be a new topic in pathogenesis of IC. Also these waves can cause exacerbation of disease in IC patients.

Limitations of our study are not linking histological changes to clinical data, not performing urodynamic examination, not using mobile phones compatible for the size of rats and using mobile phones more than average use in daily life.

\section{CONCLUSIONS}

Mast cells, which are one of the immunological cells derived from bone marrow may have important roles in etiology of non-allergic inflammatory bladder, gastrointestinal and skin diseases in experimental model of inflammation. Intensive use of mobile phones has side effects on many organs like bladder, and can cause an increase in both the number and activity of mast cells. This situation may play a role in the etiology of inflammatory bladder disease. It also can lead to exacerbate of these disorders. In diseases caused by inflammation and mast cells, minimal use of mobile phones or taking precautions to limit exposure will facilitate keeping these diseases under control.

\section{CONFLICT OF INTEREST}

None declared.

\section{REFERENCES}

1. Rothman KJ: Epidemiological evidence on health risks of cellular telephones. Lancet. 2000; 356: 1837-40. 
2. Nakamura H, Matsuzaki I, Hatta K, Nobukuni $Y$, Kambayashi Y, Ogino K: Nonthermal effects of mobile-phone frequency microwaves on uteroplacental functions in pregnant rats. Reprod Toxicol. 2003; 17: 321-6.

3. Malyapa RS, Ahern EW, Straube WL, Moros EG, Pickard WF, Roti Roti JL: Measurement of DNA damage after exposure to electromagnetic radiation in the cellular phone communication frequency band (835.62 and $847.74 \mathrm{MHz}$ ). Radiat Res. 1997; 148: 618-27.

4. Curhan GC, Speizer FE, Hunter DJ, Curhan SG, Stampfer MJ: Epidemiology of interstitial cystitis: a population based study. J Urol. 1999; 161: 549-52.

5. Parsons CL, Lilly JD, Stein P: Epithelial dysfunction in nonbacterial cystitis (interstitial cystitis). J Urol. 1991; 145: 732-5.

6. Theoharides TC, Sant GR, el-Mansoury M, Letourneau R, Ucci AA Jr, Meares EM Jr.: Activation of bladder mast cells in interstitial cystitis: a light and electron microscopic study. J Urol. 1995; 153: 629-36.

7. Cook CM, Thomas AW, Prato FS: Human electrophysiological and cognitive effects of exposure to ELF magnetic and ELF modulated RF and microwave fields: a review of recent studies. Bioelectromagnetics. 2002; 23: 144-57.

8. Hossmann KA, Hermann DM: Effects of electromagnetic radiation of mobile phones on the central nervous system. Bioelectromagnetics. 2003; 24: 49-62.
9. Braune S, Riedel A, Schulte-Mönting J, Raczek J: Influence of a radiofrequency electromagnetic field on cardiovascular and hormonal parameters of the autonomic nervous system in healthy individuals. Radiat Res. 2002; 158: 352-6.

10. Theoharides TC, Kempuraj D, Sant GR: Mast cell involvement in interstitial cystitis: a review of human and experimental evidence. Urology. 2001; 57: 47-55.

11. Pothoulakis C, Castagliuolo I, LaMont JT: Nerves and Intestinal Mast Cells Modulate Responses to Enterotoxins. News Physiol Sci. 1998; 13:58-63.

12. Chiu A, Chon SY, Kimball AB: The response of skin disease to stress: changes in the severity of acne vulgaris as affected by examination stress. Arch Dermatol. 2003; 139: 897-900.

13. Soler R, Bruschini H, Martins JR, Dreyfuss JL, Camara NO, Alves MT, et al.: Urinary glycosaminoglycans as biomarker for urothelial injury: is it possible to discriminate damage from recovery? Urology. 2008; 72: 937-42.

\section{Correspondence address:} Orhan KOCA, MD Haydarpasa Numune Training and Research Hospital Üsküdar, Istanbul, Turkey Fax: +90 216 345-5982 E-mail: drorhankoca@hotmail.com 